\title{
Accounting for Exchange-Rate Variability in Present-Value Models When the Discount Factor Is Near 1
}

\author{
By Charles Engel and Kenneth D. West*
}

A well-known stylized fact about nominal exchange rates among low-inflation advanced countries, particularly U.S. exchange rates, is that their logs are approximately random walks. Michael I. Mussa (1979) is most frequently cited for observing this regularity. In a famous pair of papers, Richard A. Meese and Kenneth Rogoff $(1983 a, b)$ found that the structural models of the 1970's could not "beat" a random walk in explaining exchange-rate movements. Recently some authors (Menzie Chinn and Meese, 1995; Nelson Mark, 1995; Mark and Donggyu Sul, 2001) have argued that the models can outforecast the random walk at long horizons. But a comprehensive recent study by Yin-Wong Cheung et al. (2003) documents that "no model consistently outperforms a random walk."

Why? One obvious explanation is that the macroeconomic variables that determine the exchange rate themselves follow random walks. If the log of the nominal exchange rate is a linear function of forcing variables that are random walks, then it will inherit the random-walk property. The problem with this explanation is that the economic "fundamentals" proposed in the most popular models of exchange rates do not, in fact, follow simple random walks.

One resolution to this problem is that there may be some other fundamentals, ones that have been proposed in some models but are not easily measurable or ones that have not yet been proposed at all, that are important in determining exchange rates. If these "unobserved" fundamentals follow random walks and dominate

* Engel: Department of Economics, University of Wisconsin, 1180 Observatory Drive, Madison, WI, 53706-1393 (e-mail: cengel@ssc.wisc.edu); West: Department of Economics, University of Wisconsin (e-mail: kdwest@ facstaff.wisc.edu). We thank Mark Watson for helpful discussion, and Camilo Tovar for excellent research assistance. Both authors thank the National Science Foundation for support for this research. the variation in exchange-rate changes, then exchange rates will nearly be random walks (even if the standard "observed" fundamentals are not).

In Engel and West (2003a) (hereinafter, EW), we propose an alternative explanation. We consider linear models of the exchange rate that are in the "asset-market approach" to exchange rates. These models emphasize the role of expectations of future economic fundamentals in determining the current exchange rate. The exchange rate (expressed as the home currency price of foreign currency in this paper) can be written as a discounted sum of the current and expected future fundamentals:

$$
\begin{array}{r}
s_{t}=x_{t l} \equiv(1-b) \sum_{j=0}^{\infty} b^{j} E\left(f_{t+j}+z_{t+j} \mid I_{t}\right) \\
0<b<1
\end{array}
$$

where $f_{t}$ and $z_{t}$ are economic fundamentals that ultimately drive the exchange rate, such as money supplies, money demand shocks, and productivity shocks. We differentiate between fundamentals observable to the econometrician, $f_{t}$, and those that are not observable, $z_{t} . E$ is the expectations operator, and $I_{t}$ is the information set of agents in the economy that determine the exchange rate.

In EW we show that if the fundamentals are I(1) (but not necessarily pure random walks), then as the discount factor approaches unity, the exchange rate will follow a process arbitrarily close to a random walk. Intuitively, we can decompose the I(1) fundamentals into the sum of a random walk and a stationary component. When the discount factor increases toward 1 , more weight is being placed on expectations of the fundamentals far into the future. Transitory components in the fundamentals become relatively less important in determining exchange-rate 
behavior. When the discount factor is near unity, the variance of the change of the discounted sum of the random-walk component in fundamentals approaches a nonzero constant, but the variance of the change of the stationary component approaches zero. Therefore, the variance of the change of the exchange rate is dominated by the change of the random-walk component, and the exchange rate becomes indistinguishable from a random walk.

In EW we argue that the theorem is a possible explanation for the random-walk-like behavior of exchange rates. In the standard models, the fundamental typically is I(1), which is a condition of the theorem. We show that empirical estimates of the discount factor are sufficiently close to 1 so that, given the time-series behavior of observed fundamentals, the exchange rate will appear to be a random walk if it is indeed determined as a discounted sum of the current and expected future fundamentals.

But is the EW result the most appealing explanation for the random walk behavior of exchange rates? We can write

$$
s_{t}=x_{t I}^{\mathrm{f}}+U_{t}
$$

where

$$
x_{t I}^{\mathrm{f}} \equiv(1-b) \sum_{j=0}^{\infty} b^{j} E\left(f_{t+j} \mid I_{t}\right) .
$$

Here, $x_{t I}^{\mathrm{f}}$ is the discounted sum of current and expected future fundamentals that the econometrician observes $\left(f_{t+j}\right)$. In this paper, we take $f_{t}$ to be the observable fundamental that emerges from one of two classes of asset-market exchange-rate models: monetary models of exchange rates developed in the 1970's, and models based on Taylor rules for monetary policy. The variable $x_{t I}^{\mathrm{f}}$ is the part of the exchange rate that can be explained from observed fundamentals; $U_{t}$ is the part of the exchange rate not determined by $x_{t I}^{\mathrm{f}}$. We take an eclectic view on what $U_{t}$ might be. It might be the case that exchange rates are determined as in equation (1), in which case $U_{t}$ is the expected discounted sum of current and future values of $z_{t}$. Or, perhaps some other type of model relates exchange rates to fun- damentals, and $U_{t}$ measures those fundamentals. Or, perhaps the exchange rate is driven in part by noise, in which case $U_{t}$ represents that noise. If $U_{t}$ is important in driving the exchange rate, then given the random-walk nature of exchange rates, $U_{t}$ must be a random walk. ${ }^{1}$ This in turn would imply that $s_{t}$ and $x_{t I}^{\mathrm{f}}$ are not cointegrated.

Our task in this paper is to get a measure of the contribution of $x_{t I}^{\mathrm{f}}$ and $U_{t}$ in driving exchange rates. We cannot say much about the contribution of $U_{t}$, since it is not observed by us. But even measuring the contribution of $x_{t I}^{\mathrm{f}}$ may appear to be a quixotic goal: $x_{t I}^{\mathrm{f}}$ is also unobservable to the econometrician (even though $f_{t}$ is observable). That is because $x_{t I}^{\mathrm{f}}$ measures agents' expectations about future fundamentals, which are not perfectly observed by the econometrician who only sees a subset of the information that agents use in forming their expectations. For example, if the economic fundamentals involve monetary policy, the econometrician might observe the time-series behavior of monetary-policy instruments and might observe many of the macroeconomic variables that influence monetary policy. But agents, in forecasting future monetary policy, have access to a wide variety of information that is difficult to quantify (e.g., newspaper and newswire reports, speeches by policymakers, etc.).

Nonetheless, this paper demonstrates that we can measure the variance of $\Delta x_{t I}^{\mathrm{f}}$ (the firstdifference of $x_{t I}^{\mathrm{f}}$ ) when the discount factor, $b$, approaches 1 . To be precise, define

$$
x_{t H}^{\mathrm{f}} \equiv(1-b) \sum_{j=0}^{\infty} b^{j} E\left(f_{t+j} \mid H_{t}\right) .
$$

Here, $H_{t}$ is the information set used by the econometrician. An estimate $\hat{x}_{t H}^{\mathrm{f}}$ can be constructed from VAR's that include $f_{t}$ and other observable macroeconomic variables that might help forecast $f_{t}$. This paper demonstrates that $\operatorname{Var}\left(\Delta x_{t H}^{\mathrm{f}}\right)$ approaches $\operatorname{Var}\left(\Delta x_{t I}^{\mathrm{f}}\right)$ when $b$ ap-

\footnotetext{
${ }^{1} U_{t}$ may be a random walk if the discounted sum of unobserved fundamentals, $z_{t}$, and $z_{t}$ is I(1) and the discount factor is near 1. In that case, the EW theorem applies to the discounted sum of expected current and future values of $z_{t}$. However, $U_{t}$ could be a random walk for any reason, not just this one.
} 
proaches 1 . To be clear, this does not mean that $x_{t I}^{\mathrm{f}} \approx x_{t H}^{\mathrm{f}}$ as $b \rightarrow 1$, and for that reason we do not look to the correlation between $\Delta s_{t}$ and $\Delta x_{t H}^{\mathrm{f}}$ to gauge the EW explanation. Although $x_{t I}^{\mathrm{f}}$ remains unobservable to the econometrician, remarkably, the variance of $\Delta x_{t I}^{\mathrm{f}}$ can be estimated consistently.

It follows from (2) that

$$
\begin{aligned}
\operatorname{Var}\left(\Delta s_{t}\right)= & \operatorname{Var}\left(\Delta x_{t I}^{\mathrm{f}}\right)+\operatorname{Var}\left(\Delta U_{t}\right) \\
& +2 \operatorname{Cov}\left(\Delta x_{t I}^{\mathrm{f}}, \Delta U_{t}\right)
\end{aligned}
$$

If only observed fundamentals matter for the exchange rate, then $\operatorname{Var}\left(\Delta s_{t}\right)=\operatorname{Var}\left(\Delta x_{t I}^{\mathrm{f}}\right)$. We will take $\operatorname{Var}\left(\Delta x_{t I}^{\mathrm{f}}\right) / \operatorname{Var}\left(\Delta s_{t}\right)$ as a measure of the importance of observed fundamentals in driving the exchange rate, when the discount factor is near 1. This satisfies our primary objective, which is to provide some insight into how effective the approach of EW is in accounting for the random-walk behavior of exchange rates.

The ability of the fundamentals to account for the variance of changes in the exchange rates differs somewhat across measures of fundamentals and across exchange rates. Roughly, we find $\operatorname{Var}\left(\Delta \hat{x}_{t H}^{\mathrm{f}}\right) / \operatorname{Var}\left(\Delta s_{t}\right)$ to be around 0.4 when we draw the fundamentals from monetary models of exchange rates, and slightly lower when the fundamentals are derived from Taylor-rule models.

\section{Asset-Market Models of Exchange Rates}

In EW, we review the familiar models that fall under the label of "the asset market approach to exchange rates." The simplest summary comes directly from Jacob A. Frenkel's (1981 pp. 674-75) paper on "news" and exchange rates, which in many ways is a precursor of our work (here we have changed only the notation to match ours):

This view of the foreign exchange market can be exposited in terms of the following simple model. Let the logarithm of the spot exchange rate on day $t$ be determined by:

$$
s_{t}=f_{t}+z_{t}+\lambda\left[E\left(s_{t+1} \mid I_{t}\right)-s_{t}\right]
$$

where $E\left(s_{t+1} \mid I_{t}\right)-s_{t}$ denotes the expected percentage change in the ex- change rate between $t$ and $t+1$, based on the information available at $t$, where $f_{t}+z_{t}$ represents the ordinary factors of supply and demand that affect the exchange rate on day $t$. These factors may include domestic and foreign money supplies, incomes, levels of output, etc. Equation (6) represents a sufficiently general relationship which may be viewed as a "reduced form" that can be derived from a variety of models of exchange rate determination.

The two types of models we consider here fall into this general form. The first is the familiar monetary model. Following Mark (1995) and others, we take the observable fundamental, $f_{t}$, to be $m_{t}-y_{t}-\left(m_{t}^{*}-y_{t}^{*}\right)$, where $m_{t}$ is the log of the domestic money supply, $y_{t}$ is the log of domestic GDP, and $m_{t}^{*}$ and $y_{t}^{*}$ are the foreign counterparts. Following the derivation in EW, the unobserved fundamental, $z_{t}$, is a linear combination of variables such as home and foreign money-demand errors, a risk premium (multiplied by $\lambda$ ), and real exchange-rate shocks arising from sources such as home and foreign productivity changes. In the monetary model, the parameter $\lambda$ represents the interest semielasticity of money demand (assumed to be identical in the home and foreign country).

The second model is less familiar and is based on Taylor-rules for monetary policy. ${ }^{2}$ In $\mathrm{EW}$, we examine the implications of an interestrate rule that has as one target (in either the home-country or foreign-country policy rule, or both) deviations of the exchange rate from its purchasing-power-parity (PPP) level, $s_{t}-\left(p_{t}-\right.$ $\left.p_{t}^{*}\right)$, where $p_{t}$ is the log of the domestic price level and $p_{t}^{*}$ is the foreign counterpart. We show that there are two different representations of the model that fall into the class of models given by (6). In the first, $f_{t}=p_{t}-p_{t}^{*}$, and $\lambda=1 / \beta$, where $\beta$ is the coefficient on deviations from (log) PPP in the Taylor rule. In this model, $z_{t}$ is a linear combination of other variables targeted by the Taylor rule as well as perhaps moneydemand errors and a risk premium. Intuitively, this model fits neatly into the framework of equation (6) because the log of the exchange

\footnotetext{
${ }^{2}$ Engel and West (2003b) explore the implications of Taylor-rule models for real exchange-rate behavior.
} 
rate is determined by its target, $f_{t}=p_{t}-p_{t}^{*}$, and the expected movement toward the target, $(1 / \beta)\left[E\left(s_{t+1} \mid I_{t}\right)-s_{t}\right]$. Another representation of the same model adds the interest differential to the difference in the log of prices, so that the observed fundamental is given by $f_{t}=p_{t}-p_{t}^{*}+$ $\left(i_{t}-i_{t}^{*}\right)$. In this case, $\lambda=(1-\beta) / \beta$. In this alternative representation, $z_{t}$ is again a linear combination of other variables targeted by the Taylor rule, money demand errors, and a risk premium. The exchange rate contains information not only about the long-run target, but also about the interest differential. The deviation of the exchange rate from its target helps markets predict the path of interest rates set by monetary policymakers.

Solving equation (6) forward for the exchange rate yields equation (1), where $b=$ $\lambda /(1+\lambda)$. Based on estimates of the interest semi-elasticity of money demand, we note in EW that in quarterly data, for the monetary model, $b \approx 0.97$ or $0.98 .^{3}$ The value of the discount factor is similar in the Taylor-rule model, based on estimates of the responsiveness of interest rates to exchange-rate targets in monetary policymaking rules.

\section{The Data}

We use quarterly data, with most data spanning 1973:1-2003:1. ${ }^{4}$ The United States is the home country, and we measure exchange rates and fundamentals relative to the other G7 countries: Canada, France, Germany, Italy, Japan, and the United Kingdom.

The exchange rates (end-of-quarter) and consumer prices (CPI) come from the International Financial Statistics CD-ROM for all seven countries. Seasonally adjusted money supplies come from the OECD's Main Economic Indicators available on Datastream, (M4 for the United Kingdom, M1 for the other countries).

\footnotetext{
${ }^{3}$ For example, the estimates of the semi-elasticity in James H. Stock and Mark P. Watson (1993) are around 0.11 . Stock and Watson express interest rates in percentages and use annual rates. To get the units correct for equation (6), we want to express interest rates in decimal form, and we are considering a quarterly frequency. So we multiply their estimate by 400 , which implies an interest semielasticity of 44, and $b=44 / 45$, or approximately 0.978 .

${ }^{4}$ For the precise data spans for each sample, see Engel and West (2004).
}

For real seasonally adjusted GDP, the data come from the OECD with the exception that for Germany the data combine IFS data (1974: 1-2001:1) with data from the OECD after 2002:1. Interest rates are three-month Euro rates from Datastream. We take logs of all data but interest rates, and we multiply all data by 100 . We use a measure of U.S. money supply that adds "sweep account programs" to our measure of M1 from the OECD. "Sweeps" refer to balances that are moved by U.S. banks from checking accounts to various interest-earning accounts by automated computer programs as a way for banks to reduce their required reserve holdings. It has been argued that exclusion of sweeps from the M1 data will lead to an undermeasurement of true transactions balances. ${ }^{5}$ The data on sweeps is obtained from the web site of the Federal Reserve Bank of St. Louis.

We examine, then, the behavior of three observed fundamentals: $m_{t}-y_{t}-\left(m_{t}^{*}-y_{t}^{*}\right), p_{t}-$ $p_{t}^{*}$, and $p_{t}-p_{t}^{*}+\left(i_{t}-i_{t}^{*}\right)$, for six countries relative to the United States. We performed augmented Dickey-Fuller tests (with four lags) with a constant and trend for all fundamentals and exchange rates, and we failed to reject the null hypothesis of a unit root in almost all cases. ${ }^{6}$ We proceeded to test for no cointegration between the exchange rate and the corresponding four fundamentals. In almost every case, we were unable to reject the null of no cointegration using Johansen's $\lambda_{\max }$ and $\lambda_{\text {trace }}$ tests. ${ }^{7}$ This latter finding suggests that there may be a role for unobserved unit-root variables [the $U_{t}$ from equation (2)] in driving exchange rates.

\section{Accounting for the Variance of Exchange-Rate Changes}

If only observed fundamentals determined exchange rates, then we would have $s_{t}=x_{t t}^{\mathrm{f}}$, where $x_{t I}^{\mathrm{f}}$ is defined in equation (3). As we have noted, we cannot measure $x_{t I}^{\mathrm{f}}$ because we do not have access to all of the information that mar-

\footnotetext{
${ }^{5}$ We thank J. Huston McCulloch for pointing out this issue to us.

${ }^{6}$ The exceptions were for the fundamentals involving prices, for Japan and Italy.

${ }^{7}$ The exceptions were for the United Kingdom, for the fundamentals involving prices.
} 
kets use in forming their expectations of future fundamentals. Here we show that we can, however, measure the variance of $\Delta x_{t l}^{\mathrm{f}}$, when the discount factor, $b$, is close to 1 . We ask whether the variance of $\Delta x_{t I}^{\mathrm{f}}$ is a substantial fraction of the variance of $\Delta s_{t}$, so that observed fundamentals can account for much of the variance in the change of log exchange rates.

We can measure $x_{t H}^{\mathrm{f}}$ as defined in equation (4) - the discounted sum of current and expected future fundamentals based on the econometrician's information, $H_{t}$. Define the innovation in $x_{t I}^{\mathrm{f}}$ as

$$
e_{t I}^{\mathrm{f}} \equiv x_{t I}^{\mathrm{f}}-E\left(x_{t I}^{\mathrm{f}} \mid I_{t-1}\right)
$$

and the innovation in $x_{t H}^{\mathrm{f}}$ as

$$
e_{t H}^{\mathrm{f}} \equiv x_{t H}^{\mathrm{f}}-E\left(x_{t H}^{\mathrm{f}} \mid H_{t-1}\right) .
$$

Under the assumption that all the variables in $I_{t}$ follow an $\operatorname{ARIMA}(q, r, s)$ process, $q, r, s \geq 0$, and that $H_{t}$ is a subset of $I_{t}$ that includes at least current and past values of $f_{t}$, equation (6) in West (1988) shows that

$$
\operatorname{Var}\left(e_{t H}^{\mathrm{f}}\right)=\frac{1-b^{2}}{b^{2}} \operatorname{Var}\left(x_{t H}^{\mathrm{f}}-x_{t I}^{\mathrm{f}}\right)+\operatorname{Var}\left(e_{t I}^{\mathrm{f}}\right)
$$

As $b \rightarrow 1, \operatorname{Var}\left(x_{t H}^{\mathrm{f}}-x_{t I}^{\mathrm{f}}\right)$ stays bounded, but $\left(1-b^{2}\right) / b^{2} \rightarrow 0$. It follows that for $b$ near 1 , $\operatorname{Var}\left(e_{t H}^{\mathrm{f}}\right) \approx \operatorname{Var}\left(e_{t I}^{\mathrm{f}}\right)$.

The EW theorem shows that when $b$ is near 1 , $\Delta x_{t I}^{\mathrm{f}} \approx e_{t I}^{\mathrm{f}}$, and $\Delta x_{t H}^{\mathrm{f}} \approx e_{t H}^{\mathrm{f}}$. Therefore, we can use an estimate of $\operatorname{Var}\left(\Delta x_{t H}^{\mathrm{f}}\right)$ to measure $\operatorname{Var}\left(\Delta x_{t I}^{\mathrm{f}}\right)$.

A simple example may help develop intuition. Suppose $f_{t}=f_{t-1}+e_{1, t}+e_{2, t-1}$, where $e_{1, t}$ and $e_{2, t}$ are mutually independent, independently and identically distributed, mean-zero processes. Assuming agents observe $e_{1, t}$ and $e_{2, t}$ at time $t$, we can use (3) to solve and find $s_{t}$ $\left(=x_{t I}^{\mathrm{f}}\right)=f_{t}+b e_{2, t}$. Then, $\Delta s_{t}\left(=\Delta x_{t I}^{\mathrm{f}}\right)=\Delta f_{t}+$ $b \Delta e_{2, t}=e_{1, t}+b e_{2, t}+(1-b) e_{2, t-1}$. As $b \rightarrow 1$, $\Delta s_{t}\left(=\Delta x_{t I}^{\mathrm{f}}\right) \rightarrow e_{1, t}+e_{2, t}$. Note that, as in the EW theorem, when $b$ approaches $1, s_{t}$ approaches a random walk.

Now, continuing with the example, suppose that $H_{t}$ contains only current and lagged values of $f_{t}$. Then, solving using equation (4), we find $x_{t H}^{\mathrm{f}}=f_{t}$, so $\Delta x_{t H}^{\mathrm{f}}=\Delta f_{t}=e_{1, t}+e_{2, t-1}$. We see in this example that as $b$ nears $1, \operatorname{Var}\left(\Delta x_{t I}^{\mathrm{f}}\right) \rightarrow$ $\operatorname{Var}\left(e_{1, t}+e_{2, t}\right)=\operatorname{Var}\left(e_{1, t}+e_{2, t-1}\right)=$ $\operatorname{Var}\left(\Delta x_{t H}^{\mathrm{f}}\right)$. This equality holds even though $\Delta x_{t I}^{\mathrm{f}}$ $\neq \Delta x_{t H}^{\mathrm{f}}$ (even as $\left.b \rightarrow 1\right)$. In this example, the EW result completely explains the random walk in $s_{t}$ as $b \rightarrow 1$, but that does not mean the exchange-rate change can be completely explained by observable changes in $f_{t}$. The correlation between $\Delta s_{t}$ and $\Delta x_{t H}^{\mathrm{f}}\left[=\operatorname{corr}\left(e_{1, t}+e_{2, t}\right.\right.$, $\left.\left.e_{1, t}+e_{2, t-1}\right)\right]$ could be far less than 1 if the variance of $e_{2, t}$ is large. ${ }^{8}$

\section{Results}

In this section, we report estimates of $\operatorname{Var}\left(\Delta x_{t H}^{\mathrm{f}}\right) / \operatorname{Var}\left(\Delta s_{t}\right)$ for our three measures of observed fundamentals: $m_{t}-y_{t}-\left(m_{t}^{*}-y_{t}^{*}\right)$, $p_{t}-p_{t}^{*}$, and $p_{t}-p_{t}^{*}+\left(i_{t}-i_{t}^{*}\right)$. In calculating this statistic, we take the econometrician's information set to be only the current and lagged value of the fundamental in each case. ${ }^{9}$

To motivate our calculation of $\operatorname{Var}\left(\Delta x_{t H}^{\mathrm{f}}\right)$, let $\mathbf{W}_{t}$ be a $(n \times 1)$ vector of observable variables, with $f_{t}=\mathbf{a}^{\prime} \mathbf{W}_{t}$. Assume that $\Delta \mathbf{W}_{t}$ follows a VAR of order $d$ :

$$
\begin{aligned}
\Delta \mathbf{W}_{t}= & \boldsymbol{\Phi}_{1} \Delta \mathbf{W}_{t-1}+\boldsymbol{\Phi}_{2} \Delta \mathbf{W}_{t-2}+\cdots \\
& +\boldsymbol{\Phi}_{d} \Delta \mathbf{W}_{t-d}+\boldsymbol{\varepsilon}_{\mathbf{W}_{t}} .
\end{aligned}
$$

Define $\boldsymbol{\zeta}(b) \equiv\left[\mathbf{I}-b \boldsymbol{\Phi}_{1}-\cdots-b^{d} \boldsymbol{\Phi}_{d}\right]^{-1}$. Then using equation (4), we can write the innovation in $x_{t H}^{\mathrm{f}}$ as:

$$
e_{t H}^{\mathrm{f}}=\mathbf{a}^{\prime} \zeta(b) \boldsymbol{\varepsilon}_{\mathbf{W}_{t}} .
$$

From the EW theorem, for $b \approx 1$, we have $\Delta x_{t H}^{\mathrm{f}} \approx \mathbf{a}^{\prime} \boldsymbol{\zeta}(b) \boldsymbol{\varepsilon}_{\mathbf{W}}$.

Mechanically, then, we estimate an autoregression (with four lags in all cases) on each measure of the fundamentals. We use estimates $\hat{\boldsymbol{\zeta}}(b) \equiv\left[\mathbf{I}-b \hat{\boldsymbol{\Phi}}_{1}-\cdots-b^{4} \hat{\boldsymbol{\Phi}}_{4}\right]^{-1}$ and $\hat{\boldsymbol{\varepsilon}}_{\mathbf{W}_{t}}$ to construct $\Delta \hat{x}_{t H}^{\mathrm{f}}=\mathbf{a}^{\prime} \hat{\boldsymbol{\zeta}}(b) \hat{\boldsymbol{\varepsilon}}_{\mathbf{W}_{t}}$.

\footnotetext{
${ }^{8}$ Mark Watson has pointed out to us that if $U_{t}=0$, then as the discount factor approaches 1 , the long-run correlation between the change in $x_{t H}^{\mathrm{f}}$ and the change in the exchange rate should approach 1 . We do not implement this useful observation here.

${ }^{9}$ For additional empirical results, see Engel and West (2004).
} 
TABle 1 -Estimates of $\operatorname{Var}\left(\Delta x_{t H}^{\mathrm{f}}\right) / \operatorname{Var}\left(\Delta s_{t}\right)$ (CuRRent AND LAGGED FundaMENTALS ONLY IN $H_{t}$ )

\begin{tabular}{|c|c|c|c|c|}
\hline \multirow[b]{2}{*}{ Country } & \multirow[b]{2}{*}{$b$} & \multicolumn{3}{|c|}{ Fundamental } \\
\hline & & $\begin{array}{c}m-y- \\
\left(m^{*}-y^{*}\right)\end{array}$ & $p-p^{*}$ & $\begin{array}{c}p-p^{*}+ \\
i-i^{*}\end{array}$ \\
\hline \multirow[t]{4}{*}{ Canada } & 0.90 & 1.142 & 0.164 & 0.162 \\
\hline & 0.95 & 1.181 & 0.188 & 0.181 \\
\hline & 0.99 & 1.213 & 0.211 & 0.199 \\
\hline & 1.00 & 1.221 & 0.218 & 0.204 \\
\hline \multirow[t]{4}{*}{ France } & 0.90 & 0.269 & 0.054 & 0.070 \\
\hline & 0.95 & 0.309 & 0.095 & 0.100 \\
\hline & 0.99 & 0.352 & 0.187 & 0.146 \\
\hline & 1.00 & 0.365 & 0.233 & 0.163 \\
\hline \multirow[t]{4}{*}{ Germany } & 0.90 & 0.257 & 0.050 & 0.054 \\
\hline & 0.95 & 0.301 & 0.077 & 0.071 \\
\hline & 0.99 & 0.349 & 0.127 & 0.095 \\
\hline & 1.00 & 0.364 & 0.148 & 0.103 \\
\hline \multirow[t]{4}{*}{ Italy } & 0.90 & 0.316 & 0.146 & 0.143 \\
\hline & 0.95 & 0.360 & 0.245 & 0.226 \\
\hline & 0.99 & 0.407 & 0.447 & 0.376 \\
\hline & 1.00 & 0.421 & 0.543 & 0.441 \\
\hline \multirow[t]{4}{*}{ Japan } & 0.90 & 0.364 & 0.039 & 0.020 \\
\hline & 0.95 & 0.406 & 0.058 & 0.023 \\
\hline & 0.99 & 0.446 & 0.090 & 0.026 \\
\hline & 1.00 & 0.458 & 0.103 & 0.027 \\
\hline \multirow{4}{*}{$\begin{array}{l}\text { United } \\
\text { Kingdom }\end{array}$} & 0.90 & 0.444 & 0.139 & 0.152 \\
\hline & 0.95 & 0.540 & 0.201 & 0.206 \\
\hline & 0.99 & 0.645 & 0.298 & 0.284 \\
\hline & 1.00 & 0.677 & 0.336 & 0.312 \\
\hline
\end{tabular}

Table 1 reports $\operatorname{Var}\left(\Delta \hat{x}_{t H}^{\mathrm{f}}\right) / \operatorname{Var}\left(\Delta s_{t}\right)$. When the fundamentals are $m_{t}-y_{t}-\left(m_{t}^{*}-y_{t}^{*}\right)$ from the monetary model, the notable result is that this ratio is fairly large, around 0.4 for most countries. Not surprisingly, the ratio rises as $b$ increases toward 1. For one country, Canada, the results are troubling for both sets of fundamentals, because the ratio exceeds 1 in all cases. From equation (5), that finding is sensible only when $\operatorname{Cov}\left(\Delta x_{t}^{\mathrm{f}}, \Delta U_{t}\right)<0$. That is, there must be a negative correlation between the change in the discounted sum of current and expected future fundamentals with the unobserved $\Delta U_{t}$.

Table 1 also looks at the fundamentals $p_{t}-p_{t}^{*}$ and $p_{t}-p_{t}^{*}+\left(i_{t}-i_{t}^{*}\right)$ from the Taylor-rule model. We find here that $\operatorname{Var}\left(\Delta \hat{x}_{t H}^{\mathrm{f}}\right) / \operatorname{Var}\left(\Delta s_{t}\right)$ is a bit lower than we found for the fundamentals from the monetary model. When $b=0.95$ or 0.99 , for most countries the ratio is around 0.20 , though it is about half that size for Germany and Japan. In this case, all of the ratios are less than 1 , but only in the case of Italy, when $b=1$ and the fundamental is $p_{t}-p_{t}^{*}$, does the ratio exceed 0.5 .

There are few previous studies that permit comparison to these figures. The bounds on the variance of $\Delta s_{t}$ and of $s_{t}-E_{t-1}\left(s_{t}\right)$ of Roger D. Huang (1981 p. 37) and Behzad T. Diba (1987 p. 106) use inequalities that are satisfied by construction for $b$ arbitrarily near 1 . Such inequalities unhelpfully guarantee values greater than 1 for the ratio that we consider. Using the monetary model, West (1987 p. 70) finds a ratio of about 0.02-0.08 for the Deutschemark-dollar exchange rate. The present technique yields considerably higher figures, suggesting there is rather more in the monetary model than this previous volatility test would suggest.

We conclude that asset-market models in which the exchange rate is expressed as a discounted sum of the current and expected future values of these observed fundamentals can account for a sizable fraction of the variance of $\Delta s_{t}$ when the discount factor is large. The EW explanation for a random walk provides a rationale for a substantial fraction of the movement in exchange rates. But there is still a role for left-out forcing variables: perhaps moneydemand errors, a risk premium, mismeasurement of the fundamentals we have examined here, some other variables implied by other theories, or noise.

\section{REFERENCES}

Cheung, Yin-Wong; Chinn, Menzie D. and Garcia Pascual, Antonio. "Empirical Exchange Rate Models of the Nineties: Are Any Fit to Survive?" Working paper, University of California-Santa Cruz, 2003.

Chinn, Menzie D. and Meese, Richard A. "Banking on Currency Forecasts: How Predictable Is Change in Money?" Journal of International Economics, February 1995, 38(1-2), pp. 161-78.

Diba, Behzad T. “A Critique of Variance Bounds Tests for Monetary Exchange Rate Models: Note." Journal of Money, Credit and Banking, February 1987, 19(1), pp. 104-111.

Engel, Charles and West, Kenneth D. "Exchange Rates and Fundamentals." Working paper, University of Wisconsin, 2003a. 
. "Taylor Rules and the DeutschmarkDollar Exchange Rate.” Working paper, University of Wisconsin, 2003b.

. "Accounting for Exchange Rate Variability in Present-Value Models When the Discount Factor Is Near One." National Bureau of Economic Research (Cambridge, MA) Working Paper No. 10267, January 2004.

Frenkel, Jacob A. "Flexible Exchange Rates, Prices, and the Role of 'News': Lessons from the 1970s." Journal of Political Economy, August 1981, 89(4), pp. 665-705.

Huang, Roger D. "The Monetary Approach to Exchange Rate in an Efficient Market: Tests Based on Volatility." Journal of Finance, March 1981, 36(1), pp. 31-41.

Mark, Nelson. "Exchange Rates and Fundamentals: Evidence on Long-Horizon Predictability." American Economic Review, March 1995, 85(1), pp. 201-18.

Mark, Nelson and Sul, Donggyu. "Nominal Exchange Rates and Monetary Fundamentals: Evidence from a Small post-Bretton Woods Sample." Journal of International Economics, February 2001, 53(1), pp. 29-52.

Meese, Richard A. and Rogoff, Kenneth. "Empir- ical Exchange Rate Models of the Seventies: Do They Fit Out of Sample?" Journal of International Economics, February 1983a, 14(1-2), pp. 3-24.

. "The Out of Sample Failure of Empirical Exchange Models," in Jacob A. Frenkel, ed., Exchange rates and international macroeconomics. Chicago, IL: University of Chicago Press, 1983b, pp. 67-105.

Mussa, Michael I. "Empirical Regularities in the Behavior of Exchange Rates and Theories of the Foreign Exchange Market," in Karl Brunner and Allan H. Meltzer, eds., Policies for employment, prices, and exchange rates. New York: North Holland, 1979, pp. 9-57.

Stock, James H. and Watson, Mark P. "A Simple Estimator of Cointegrating Vectors in Higher Order Autoregressive Systems." Econometrica, July 1993, 61(4), pp. 783-820.

West, Kenneth D. "A Standard Monetary Model and the Variability of the DeutschemarkDollar Exchange Rate." Journal of International Economics, August 1987, 23(1/2), pp. 57-76.

. "Dividend Innovations and Stock Price Volatility." Econometrica, January 1988, 56(1), pp. 37-61. 